\title{
Microwave Fruit and Vegetables Drying
}

\author{
Rohini K Parit ${ }^{1}$, Ms. Chatali S. Prabhu² \\ Lecturer, I.E. Dept Government Polytechnic, Kolhapur, India ${ }^{1,2}$
}

\begin{abstract}
Drying is one of the most popular and common fruit preservation technique. Fruits are dried to extend storage life and reduce transport weight. The use of microwaves in drying has been growing in recent years. Now a day's microwave drying is the most common method for fruits. In resent research on microwave drying have some limitations like excessive heating at the edges and corners of the product. Due to this scorching problem are occurred also it causes the off-flavor. To reduce the energy wastage and operational cost new dimensions came up in drying techniques. The advantages of MW combination drying techniques include shorter drying times, improved product quality and Flexibility in producing a wide variety of dried products. The drying rate can be significantly increased; the nutritional value, color, and original flavor can be largely maintained; puffing, drying, and sterilization are accomplished simultaneously to enhance the overall product quality; heat loss is decreased because the drying time is shortened and the difference in temperature between the inside and outside of the equipment is small; energy absorption is proportional to the residual moisture content and can be easy controlled; and MW drying can be performed at lower temperatures suitable for processing heat-sensitive materials.
\end{abstract}

Keywords: Microwave, vacuum Drying, Energy saving, conventional heating.

\section{INTRODUCTION}

Fruit drying is the process of removing moisture. Fresh fruits or vegetables last for few days; if we use the drying methods for fruit preservation then they can be stored for months or even years. Drying is defined as simultaneous heat and mass transfer operation in which water activity of material is lowered by the removal of water by evaporation into an unsaturated gas stream. [1]. The development of new, high quality and customer attractive dried fruit product is need of the market. Hot air drying is the most common method to preserve fruits but due to this method it causes the dehydration of product. Also this process has negative impact on product quality due to the long drying time and high temperature employed. The quality of the conventionally dried product is lower than the original product with an impact on color, texture and other characteristics. Preservation of fruit with drying by sun and solar technique, yield poor quality.

The dried product's quality depends upon the drying conditions and methods to be used. To reduce these problems, faster and more effective drying process, such as microwave drying method, should be considered for fruit dehydration. Recently, microwave drying method has been proposed as a efficient drying alternative to conventional hot air drying. Microwave leads to a volumetric heating which means that all the materials like fruits and vegetables can be heated to the desired temperature at the same time. In the microwave heating, microwaves are directly absorbed and convert it in to the heat. Heating process is started from the inside of the fruit and this is faster than the conventional heating.

Advantage of microwave heating is the shorter drying time, improved food quality and original flavor can be maintained. Due to shorter drying time heat loss also minimized. Microwave drying can be operated at lower temperatures suitable for processing heat-sensitive materials. In microwave all the material can be heated to the desired temperature at the same time.

One of the applications of microwave drying is in food industries to make different flavors of different fruits.

\section{MICROWAVE DRYING}

The microwave generator (magnetron) produced microwaves with varying power densities based on the supplied power. The generated microwaves were guided using the waveguides into the microwave cavity [2]. Microwave drying uses electrical energy in the frequency range of $300 \mathrm{MHz}$ to $300 \mathrm{GHz}$. The most commonly used frequency is 2,450 MHz. Microwaves are generated inside an oven. This is done with the help of the magnetron tube. Microwave drying offers to shorten the drying time without degradation of final quality of the dried product. The use of microwave energy for drying has been demonstrated to have moderately low energy consumption. When the material couples with microwave energy, heat is generated within the product through molecular excitation. The critical next step is to immediately remove the water vapour. A simple technique for removing water is to pass air over the surface of the material hence combining processes to form what is called "microwave convective drying".

\section{MICROWAVE CONVECTION AND MICROWAVE VACUUM DRYING}

Since the boiling point of water is reduced at lower pressures, vacuum can be applied to microwave drying to 
improve product quality. There have been numerous studies on the application of vacuum to microwave drying.[12] Microwave drying has a big advantage compaired with conventional drying, because in microwave drying heat is generated by directly transforming the electromagnetic energy in to kinetic molecular energy, thus the heat is generated deep within the product to be dried. Microwaves are not forms of heat but rather forms of energy that are prove as heat through their interaction with materials. Most of the moisture is vaporized before leaving the material. If the material is very wet and the pressure inside rises rapidly the liquid will be removed from the material due to the difference in pressure. This results in very rapid drying without the need to overheat the atmosphere and perhaps cause case hardening or other surface overheating phenomena.

\section{ENERGY SAVING AND BENEFITS OVER CONVENTIONAL HEATING}

1. Reduce man-hours and downtime involved in cleaning

2. Smaller equipment footprint

3. Eliminate warm up and cool down time

4. Microwave energy does not heat the room only the material

Microwave drying works fast. This is because instead of applying energy only to the outside of the product, microwaves work directly to dry material from the inside out. Most conventional heating and drying methods approach material from the surface, applying heat only to the outside edges. This technique removes surface moisture very quickly, but it is highly inefficient when it comes to removing liquid trapped inside the material. If external temperatures are kept high enough, as in an oven, the material's inner moisture will diffuse to the surface and evaporate, but this is a passive and lengthy process.

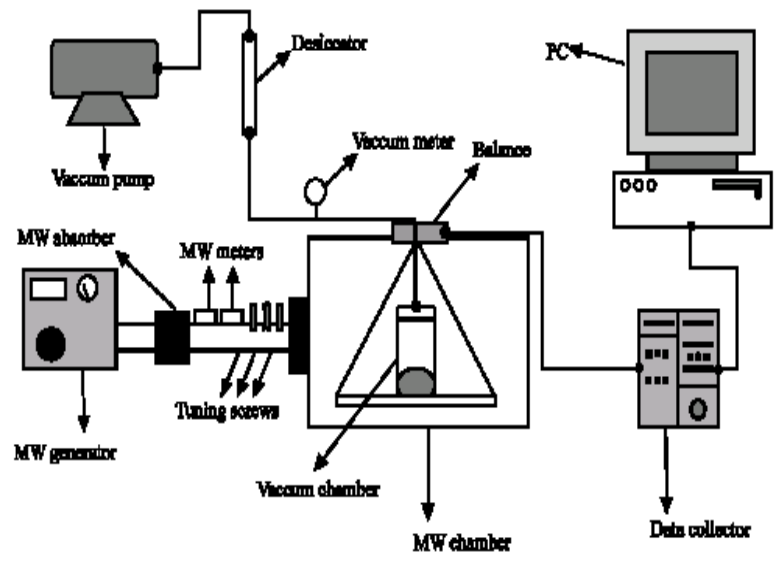

Fig.1:- microwave vacuum dryer

By contrast, in microwave heating, moisture is forced out in the form of a vapor, such as steam. It can dry most materials in less of the time required by conventional methods.

\section{MICROWAVE DRYING OF TOMATO SLICE}

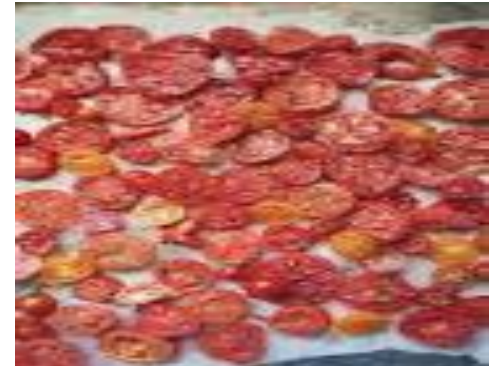

Fig.2:- Microwave drying of tomato slice

In Microwave drying tomato slice was sampled, From the starting of the drying the change in the sample weight was recorded at the time intervals of 2 minutes. The drying tests were terminated when the moisture content indicated $10 \%$. The final moisture content of each sample was measured in order to calculate the moisture content at each weighing interval. Among several subjective quality attributes of dried tomato slices the colour is an important one which indicates the level of effects of different drying methods or conditions. Drying using $1.13 \mathrm{~W}$ g-1 coupled with $50^{\circ} \mathrm{C}$ hot air ventilation and by hot air ventilation at the temperatures of 40 and $50^{\circ} \mathrm{C}$ without microwave heating was found to be the best in terms of maintaining the colour quality of the tomato slices.

\section{MICROWAVE DRYING OF APPLE}

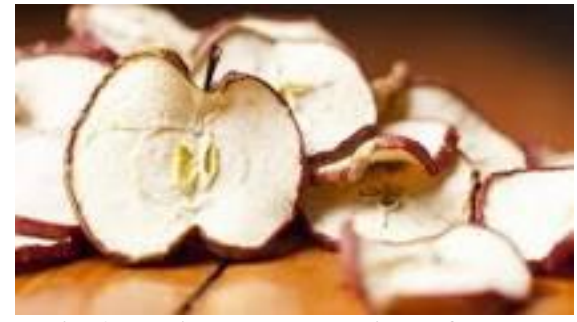

Fig.3:- Microwave drying of apple

Dried fruits are widely used as components in many food formulation such as pastry, confectionery products, ice cream, frozen desserts and yogurt. Among them, dried apples are a significant raw material for many food products. The drying process was progressed through two stages, in the first stage the samples were put in a microwave oven until drying took place mainly in constant rate period, approximately $55 \%$ of the water was removed in this period. After that the forced draft oven was used until the apple samples reached the final moisture content. The second stage, the apple samples were put in forced draft oven to reach the final moisture content. For one hour or two hours The value of the drying constant increased with increased microwave output power. The change in color values was dependent on the pretreatment. The $45 \%$ sugar solution showed decrease drying rate than the other treatment. The increasing on the density power $(\mathrm{W} / \mathrm{g})$ the drying rate increased by $35 \%$. 
The drying apple process, the apple samples could be Selective and volumetric heating effects, microwaves microwave dried to $20 \%$ moisture content wet basis in few minutes (rang 3 to 5 minutes).

\section{MICROWAVE-VACUUM DRYING OF STRAWBERRIES}

These fruits have a delicate sweet-smelling flavor and very pleasant bittersweet taste. However, strawberries are easily degraded by spoilage due to their high moisture content, about $90 \%$ (wet basis). Strawberries are mainly used in jams, dairy products, biscuits and cookies, preserved foods, and syrups or could be directly consumed as fresh or dehydrated fruit. Chile is currently exporting $16 \%$ of its production of dried fruits to the USA, $14 \%$ to Mexico, and $10 \%$ to Europe (Central Bank, Chile 2014). Hence, there is a clear economic incentive in the dehydration of types of fruits. The vacuum-microwave drying system operated for $2.5 \mathrm{~h}$ at a temperature between 40 and $60^{\circ} \mathrm{C}$.

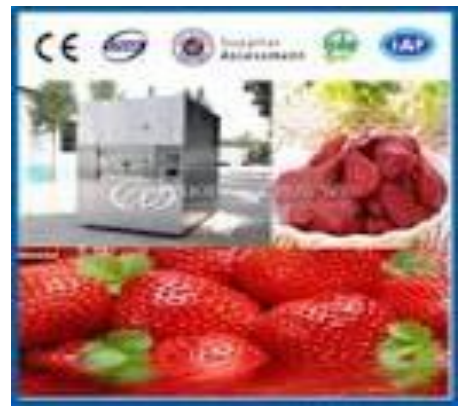

Fig.4:- Microwave drying of Strawberries

An optimal location of magnetron with a suitable microwave power improves the drying uniformity of fruit. The energy received by the fruit was the difference between that provided by the magnetron and the one consumed in heating water.

\section{MICROWAVE DRYING OF LEMON SLICES}

Lemon samples placed at room temperature for $4 \mathrm{~h}$ to reach thermal equilibrium with the environment. For each experiment, the lemons were cut into $4 \mathrm{~mm}$ thickness slices perpendicular to the fruit axis and approximately $200 \mathrm{~g}$ of the samples (lemon slices with peel) were spread thinly as a monolayer on tray in an air ventilated oven. Lemon slices were dried in an air ventilated oven dryer at temperatures of 50, 60 and $75^{\circ} \mathrm{C}$. Drying temperature had a significant effect on drying time where the process time for drying temperatures of 50,60 and $75^{\circ} \mathrm{C}$ was about 4350, 2120 and $1100 \mathrm{~min}$, respectively. No constant rate period was seen and the entire drying processes occurred in the falling rate period.

\section{CONCLUSION}

Many new dimensions came up in drying technology to reduce the energy utilization and operational cost. bring new characteristics such as increased rate of drying, enhanced final product quality and improved energy consumption. Combination drying with an initial conventional drying process followed by a microwave finish or microwave vacuum process has proven to reduce drying time while improving product quality and minimising energy requirements. However, several factors should be taken into consideration when developing drying system for the fruits and vegetables. The microstructure of microwave-dried samples showed certain discontinuities; however, the overall mechanical strength was improved.

\section{REFERENCES}

[1] G. R. Askari , Z. Emam-Djomeh\& S. M. Mousavi (2009)" An Investigation of the Effects of Drying Methods and Conditions on Drying Characteristics and Quality Attribute of Agricultural Products during Hot Air and Hot Air/Microwave-Assisted Dehydration", Drying Technology, 27:7-8, 831-841, DOI: 10.1080/07373930902988106 (14 Aug 2009.)

[2] S. R. S. Dev , T. Padmini , A. Adedeji , Y. Gariépy\& G. S. V. Raghavan (2008) "A Comparative Study on the Effect of Chemical, Microwave, and Pulsed Electric Pretreatments on Convective Drying and Quality of Raisins”, Drying Technology, 26:10, 12381243 (11 Sep 2008)

[3] Peng Liu , Arun S. Mujumdar, Min Zhang \& Hao Jiang (2015) "Comparison of Three Blanching Treatments on the Color and Anthocyanin Level of the Microwave Assisted Spouted Bed Drying of Purple Flesh Sweet Potato", Drying Technology, 33:1, 66-71, DOI: 10.1080/07373937.2014.936558 (17 Oct 2014.)

[4] Dariusz Piotrowski, Andrzej Lenart, Andrzej Wardzy_nski "Influence of osmotic dehydration on microwave convective drying of frozen strawberries" Journal of Food Engineering 65 (2004) 519-525. (Received 23 July 2003; accepted 9 February 2004)

[5] Garcia-Noguera, Juan; Oliveira, Francisca I. P.; Gallão, Maria Izabel; Weller, Curtis L.; Rodrigues, Sueli; and Fernandes, Fabiano A. N.,"Ultrasound-Assisted Osmotic Dehydration of Strawberries: Effect of Pretreatment Time and Ultrasonic Frequency"(2010). (1 Jan 2010)

[6] Viboon Changrue, G.S. Vijaya Raghavan, Yvan Gariépy and Valérie Orsat "Microwave vacuum dryer setup and preliminary drying studies on strawberries Carrots." (31 Aug 2007)

[7] Palmiro Poltronieri, Angelo Santino, Loredana F. Ciarmiello, Jan Hubert, "Application of Microwave and RF in food processing, microorganisms and pest control" 978-1-4673-7602-0/15/\$31.00 @2015 IEEE

[8] M. Zhanga, J. Tangb, A.S. Mujumdarcand S. Wang "Trends in microwave related drying of fruits and vegetables" Trends in Food Science \& Technology 17 (2006) 524e534

[9] Thomas Kivevele, Prof. Zhongjie Huan, "Experimental comparative study of an open and completely closed air source heat pump for drying subtropical fruits" The paper is presented by Mr Thomas Kivevele (2015)

[10] Mehdi Torki-Harchegani, Mahdi Ghasemi-Varnamkhast, Davoud Ghanbarian Morteza Sadegh, Mojtaba Tohidi "Dehydration characteristics and mathematical modelling of lemon slices drying undergoing oven treatment" (C) Springer-Verlag Berlin Heidelberg 2015 (Received: 6 March 2014 / Accepted: March 2015)

[11] Suwit Paengkanya, Somchart Soponronnarit, Adisak Nathakaranakule "Application of microwaves for drying of durian chips" Food and Bioproducts Processing. (Received 10 March 2015Received in revised form 3 June 2015Accepted 8 June 2015Available online 17 June 2015)

[12] Valérie Orsat, Viboon Changrue and GS Vijaya Raghavan "Microwave drying of fruits and vegetables" (Published online 01 December 2006)

[13] Albanese, D., Cinquanta, L., Cuccurullo, G., \& Di Matteo, M. (2013). Effects of microwave and hot-air drying methods on color, $\beta$-carotene and radical scavenging activity of apricots. International Journal of Food Science and Technology, 48(6), 1327-1333. 